\title{
Long term results of Endoscopic Lumbar Discectomy using Side viewing Conical working tube
}

\author{
Mohammad Kaif ${ }^{1}$, Kuldeep Yadav, Mazhar Husain ${ }^{2}$ \\ ${ }^{1}$ M.Ch. (Neurosurgery) Assistant Professor of Neurosurgery, "Dr Ram Manohar Lohia” Institute \\ of Medical Sciences, Lucknow, (UP), INDIA \\ ${ }^{2}$ M.Ch. (Neurosurgery) Chief of Neurosurgery, Sahara Hospital, Lucknow, (UP), INDIA
}

\begin{abstract}
Object: Endoscopic discectomy is a common procure performed worldwide with various devices being used and studies have reported their long term results. In this study we present the long term results of the unique device with separate side viewing channel. Methods: 66 patients of lumbar disc herniation treated between March 2009 to April 2012 using the unique conical working tube with separate side viewing endoscopic channel. Their preoperative and postoperative Oswestry Disability Index (ODI) and Macnab scores were used to evaluate the outcome after a minimum follow of 5 years with mean follow up of 76.18 months. Results: There were 46 males and 20 females with age ranging from19-72 (mean-38.4 years). The follow up ranged from 61 months to 95 months with mean of 76.18 months. The mean preoperative ODI score was 74.7 which decreased to a mean of 7.8 and the outcome evaluated by Macnab criteria was $69.69 \%$ excellent, $17 \%$ good, $10 \%$ fair, $3.03 \%$ poor. 2 patients underwent second surgery. None of the patient had to change their occupation due to their lumbar disc disease. Complications occurred were dural tear in 2 patients, transient foot paresis in 1 patient and 1 discitis in 1 patient which improved on medical management. Conclusion: Endoscopic discectomy using thins Conical working tube is a safe and effective technique for lumbar disc prolapse. It has the advantage for early mobilization, short hospital stay and low cost. The long term results are comparable to the conventional techniques.
\end{abstract}

Key words: endoscopy, discectomy, herniated disc, prolapsed intervertebral disc, lumbar spine

\section{Introduction \\ Surgery for Prolapsed Lumbar Intervertebral disc is one of the most}

common surgery performed by spinal surgeons. Open Micro discectomy or endoscopic inter-laminar or transformational lumbar discectomy are preferred modality of 
treatment by most spinal surgeons with proven safety and outcome and each having is advantages and disadvantages. Xue-Song Wang in their meta-analysis concluded that the inter-laminar endoscopic surgery has the advantage of decreased hospital stay and blood loss in comparison to microdiscectomy and with similar results for long term pain control, functional recovery or incidence of complication [32]. Various authors have reported their experience ofendoscopic discectomy using different devices with excellent to good long term follow up. In this report with summarize the long term results of endoscopic discectomy using the conical working tube with separate viewing channel.

\section{Clinical material and methods}

This is a retrospective study based on long term follow up of 66 patients of lumbar disc herniation treated using the unique conical working tube with side viewing endoscopic channel [14]. The hospital records of 212 patients who underwent endoscopic lumbar discectomy using this device between March 2009 to April 2012 were retrieved. Only those patients were included in this study who could be contacted on telephone and responded to the ODI and Macnab fomat. The indication for surgery was low backache with radicular pain in lower limb with or without neurological deficit and failed conservative management. The patients who had segmental instability, no clinicradiological correlation or evidence of infection were excluded from this study.

There were 46 males and 20 females with age ranging from19-72 (mean-38.4 years).
The follow up ranged from 61 months to 95 months with mean of 76.18 months.

- Instrument design: this device consists of a conical working tube which is passed over coaxial dilators and secured in position by a holding device attached to the operating table. It has a separate side viewing channel for the telescope which is attached to light source and camera. No special instruments are used for laminotomy and discectomy. Figure 1.

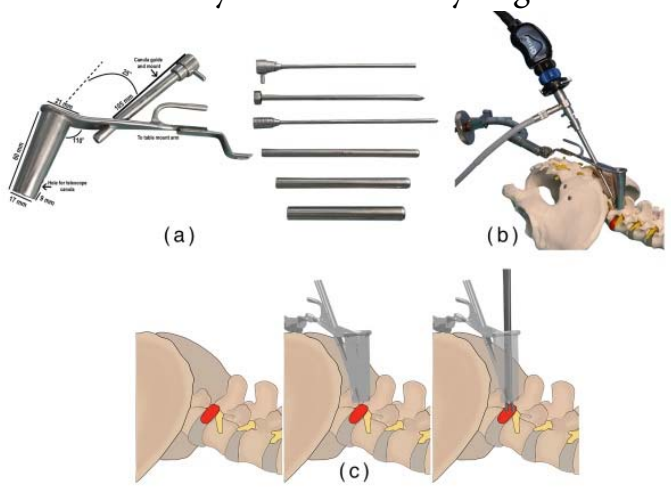

Figure 1 - Instruments design. 1a. Photograph of the device with its measurements; $1 \mathrm{~b}$. Device placed in a spine model; 1c. Diagrammatic representation of the device with disc forceps in inside the device showing the ease of using regular instruments through the device without clutter

- Operative technique: after general anesthesia the patient is positioned in prone position on a Wilson's frame or foam bolsters. The level is localised using fluoroscopy and $18-20 \mathrm{~mm}$ skin incision is given in midline. The fascial incision is made $1 \mathrm{~cm}$ lateral to midline. The first dilator is passed with a $5 \mathrm{~mm}$ trocar upto the lamina and the trocar is removed. A gentle medial to lateral and cranial and caudal sweeping movement is done for 
elevation of soft tissue. Two subsequent dilators are passed over this first tube. Finally the working tube is passed over these dilators and fixed to table. The position of the working tune is confirmed using fluoroscopy. A cannula with trocar is passed from the separate side channel through a separate stab incision and locked in the working tube using the locking mechanism. The telescope " 0 " degree, $4 \mathrm{~mm}$ diameter and $180 \mathrm{~mm}$ length is passed through this separate channel. The tip of the telescope just reaches upto the inner part of the working tube. The light source and camera is attached to the cannula and the image orientation is done by rotating the camera on scope. Figure 2.

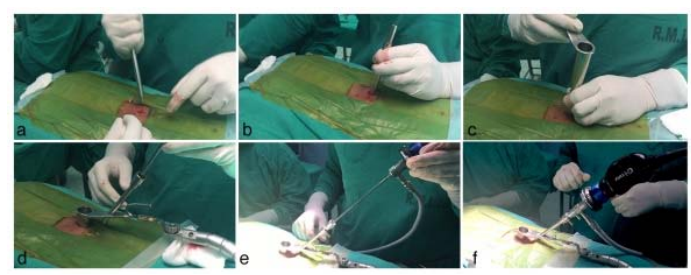

Figure 2 - steps of the procedure

2a. 1st dilator with sharp trocar being passed; 2 b. 2nd dilator being passed over the 1st dilator; $2 \mathrm{c}$. Final working tube being passed; $2 \mathrm{~d}$. Cannula for

Telescope being passed through separate channel in the working tube; $2 \mathrm{e}$. Telescope being passed; $2 \mathrm{f}$.

Complete the device assembly in situ and fixed to the operating table

The medial part of the facet and contiguous lamina are identified. A small hemiliaminotomy medial facetectomy is made using Kerrison rounger. The Ligamentum flavum is detached from the undersurface of the lamina above using an angle micro-curette. Ligamentum flavum is then removed and the traversing nerve root and thecal sac are identified using ball probe. The nerve root is retracted medially and the disc is removed by entering the disc space through the annular tear or an annulotomy with No 11 surgical blade. The disc space is irrigated with Normal Saline to wash out loose disc fragments. The nerve root is inspected to ensure adequate decompression. Figure 3, Figure 4. The entire assembly is removed and the fascia is closed with absorbable suture. Skin is closed using subcuticular sutures.

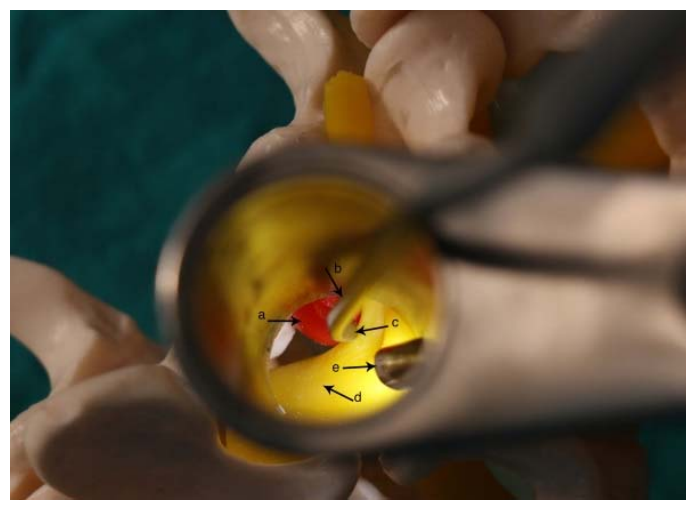

Figure 3 - Magnified view through the device 3a. Extruded disc; 3b. Dissector; 3c. Nerve root; 3d. Thecal sac; 3e. Telescope 


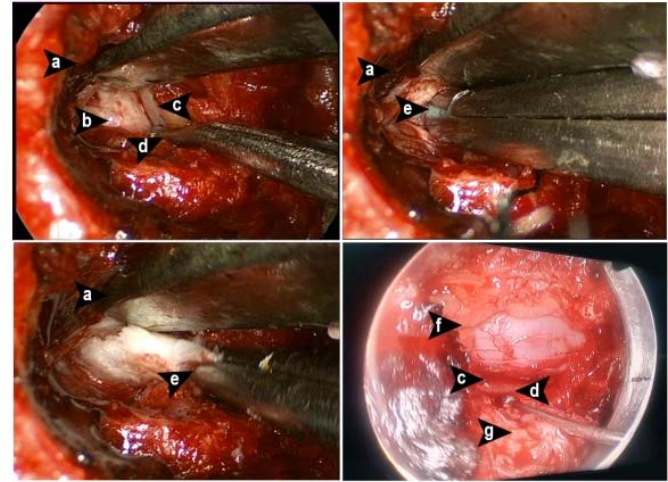

Figure 4 - Endoscopic view

4a. Nerve root retractor; $4 \mathrm{~b}$. Intervertebral disc; 4c. Nerve root; 4d. Ball Dissector; 4e Disc forceps holding the disc; 4f. Thecal sac; 4g. Facet joint

Postoperative management- Patients were mobilized in the evening of day of surgery after and discharged on the next day. In this study the mean hospital stay was 1.6 days.

\section{Complications}

The most common complication was found to incidental dural tear, observed in 2 patients. This was managed by sealing the defect by fibrin glue. No postoperative CSF leak or pseudomeningocele or any long term sequelae was observed. The other postoperative complications were transient foot paresis in 1 patient and 1 discitis in 1 patient which improved on antibiotic therapy.

\section{Results}

The patients were evaluated using ODI score and the total score was calculated. The score was interpreted into $0 \%$ to $20 \%$ (minimal disability), $21 \%$ to $40 \%$ (moderate disability), $41 \%$ to $60 \%$ (severe disability), $61 \%$ to $80 \%$ (crippled) and $81 \%$ to $100 \%$ (bed bound/ exaggerating their symptoms). Both the preoperative and postoperative ODI were compared and its difference was calculated. The outcome at the last visit was evaluated by Mcnab criteria in to excellent, good, fair and poor. The follow up ranged from 61 months to 95 months with mean being 76.18 months. The mean preoperative ODI score was 74.7 which decreased to a mean of 7.8. The outcome evaluated by Macnab criteria was 69.69\% ( $n=46)$ excellent, $17 \%(n=11)$ good, $10 \%(n=7)$ fair, $3.03 \%(n=2)$ poor.

One patient experienced persistent radicular pain of same intensity was diagnosed to have a residual disc fragment which was removed by microsurgery and the other patient developed recurrence of symptoms 2 years after 1st surgery. He was diagnosed with bony canal stenosis at the same level with instability and underwent intervertebral fusion. None of the patient had to change their occupation due to their lumbar disc disease.

\section{Discussion}

The technique of classical discectomy as described by Mixter and Barr has undergone significant change to minimize the trauma of long incision, extensive muscle dissection and laminectomy leading to prolonged post operative hospital stay, morbidity due pain, scarring around nerve root and instability [27], (Table 1). To over these disadvantages Microsurgical technique was adopted which has made a siginifinat improvement in the outcome (Table 2). 
310 Kaif et al - Long term results of Endoscopic Lumbar Discectomy

Table 1 - Studies of Open laminectomy/laminotomy with discectomy

\begin{tabular}{lccc}
\hline Author \& Year & No. of patients & Results Excellent/good- & Followup in years \\
Atlas et al. 2005 & 217 & 69 & 10 \\
Bakhsh et al. 2010 & 39 & 79 & 10 \\
Butterman et al. 2004 & 100 & 92 & 2.5 \\
Hsu et al. 2011 & 226 & 82 & 2 \\
Jansson 2004 & 22261 & 78 & 6 \\
Mariconda et al. 2006 & 201 & 90 & 27.8 \\
Martinez quinones et al. 2011 & 142 & 93 & 5 \\
\hline
\end{tabular}

Table 2 - Studies of Microdiscetomy

\begin{tabular}{lccccc} 
Author \& Year & $\begin{array}{c}\text { No. of } \\
\text { patients }\end{array}$ & Criteria & $\begin{array}{c}\text { Results } \\
\text { Excellent/Good- }\end{array}$ & $\begin{array}{c}\text { Mean Followup } \\
\text { In Years }\end{array}$ & Recurrence \\
Findlay et al. 1998 & 79 & macnab & $83 \%$ & 10 & 20.7 \\
Jensdottir et al. 2007 & 134 & & $91 \%$ & 8.6 & $12.7 \%$ \\
Moore et al. 1994 & 100 & & $93 \%$ & 6.3 & 8.5 \\
Schoeggl et al. 2003 & 672 & prolo & $77 \%$ & $81 \%$ & \\
Vik et al. 2001 & 62 & & & \\
\hline
\end{tabular}

To further minimise the disadvantages of open surgery Foley and Smith described Microendoscopic Discectomy (MED) in 1997 for root decompression in cases of lumbar disc disease [12]. Varoius authors have described their results of MED which is mentioned in Table 3.

Table 3 - Studies of Endoscopic Discectomy

\begin{tabular}{|c|c|c|c|c|c|c|}
\hline Author \& Year & $\begin{array}{l}\text { No. of } \\
\text { patients }\end{array}$ & Tech & Outcome measures & Outcome & recurrence & Complication \\
\hline Li et al. 2015 & 72 & IL & VAS,ODI, Mcnab & $97 \%$ good to excellent & 1 & No complications \\
\hline Xu et al. 2014 & 36 & $\mathrm{IL}$ & VAS & Excellent & $\begin{array}{l}2 \text { patients } \\
\text { converted to } \\
\text { open }\end{array}$ & None \\
\hline Hussein et al. 2014 & 185 & IL & NRS, Mcnab ODI & $\begin{array}{l}\text { Statistically significant } \\
\text { pain releirf }\end{array}$ & $\begin{array}{l}2 \text { converted to } \\
\text { open }\end{array}$ & 3 dural tears \\
\hline Kulkarni et al. 2014 & 188 & IL & VAS,ODI & $\begin{array}{l}\text { Statistically significant } \\
\text { pain releirf }\end{array}$ & $3(1.5 \%)$ & $\begin{array}{l}11(5 \%) \text { dural } \\
\text { tears, } 1(0.5 \%) \text { infection, } \\
1(0.5 \%) \text { wrong level }\end{array}$ \\
\hline Kim et al. 2013 & 224 & IL & VAS ODI & $\begin{array}{l}\text { Statistically significant } \\
\text { pain releirf }\end{array}$ & $5 \%$ & None \\
\hline Yadav et al. 2013 & 400 & IL & Vas, Mcnab & $\begin{array}{l}90 \% \text { significant } \\
\text { improvement }\end{array}$ & $2(0.5 \%)$ & $\begin{array}{l}3 \text { facet injuries, } 7 \text { dural tears, } 2 \\
\text { infections, } 1 \text { persistent } \\
\text { paresthesia }\end{array}$ \\
\hline Kim et al. 2012 & 18 & IL & Mcnab & $98 \%$ complete removal & 2 residual & 1 duraltera \\
\hline Kaushal et al. 2012 & 300 & IL & Mcnab & $90 \%$ excellent to good & & 2 nerve root injury \\
\hline Kim et al. 2012 & 30 & IL & & Significant improvement & & None \\
\hline Chumnanvej et al. 2011 & 60 & IL & Mcnab & $91.6 \%$ excellent outcome & 2 & None \\
\hline
\end{tabular}




\begin{tabular}{|c|c|c|c|c|c|c|}
\hline Chen et al. 2011 & 123 & IL & VAS, ODI & Significant improvement & 3 & 1 dural tear \\
\hline Dezawa et al. 2011 & 30 & IL & & $\begin{array}{l}\text { Statistically significant } \\
\text { improvement }\end{array}$ & $\begin{array}{l}1 \text { persistent } \\
\text { radiculopathy }\end{array}$ & \\
\hline Wang et al. 2011 & 30 & IL & VAS & Significant improvement & $\begin{array}{l}20 \% \text { converted to } \\
\text { open }\end{array}$ & $\begin{array}{l}4.1 \% \text { duralteras, } 4 \text { nerve root } \\
\text { injury, } 1 \mathrm{DVt}, 1 \text { discitis }\end{array}$ \\
\hline Jhala Mistry et al. 2010 & 100 & IL & Mcnab & $91 \%$ excellent to good & 4 & 4 discitis, 1 nerve root damage \\
\hline Kaif et al 2017 & 66 & IL & Mcnab,ODI & $86.36 \%$ excellent to good & $\begin{array}{c}\text { Second surgery in } \\
2\end{array}$ & $\begin{array}{l}\text { Discitis } 1 \text {, dural tear } 2, \\
\text { transiet foot paresis } 1\end{array}$ \\
\hline
\end{tabular}

Jensdottir et al in their retrospective study reported a good/excellent outcome of micro discectomy after up a mean followup of 20.7 years [17]. Casal Moro et al in their prospective study reported that MED is a safe and reproduce able technique with lesser tissue trauma with comparable results to that of conventional techniques [6]. Bhansare et al reported their 10 year experience using the Destandau technique with excellent short and long term results [4]. The other technique of minimally invasive lumbar discectomy commonly practiced via the transforaminal route through the Kambin's triangle has been reported with improvement in the Japanese Orthopedic association score of 76\% [34]. The disadvantage of this technique is that the contralateral component of the disc bulge and the diffuse bony canal stenosis are difficult to address.

The long term results with this device were excellent to good in $86.36 \%$ of cases after a mean followup of 76.18 months which is comparable with the long term studies of all the minimally invasive lumbar discectomy techniques practiced worldwide. None of the patients had to change their profession in this follow up period.

Casalmoro reported surgical complication rate of 3 to $10 \%$ in various techniques whereas Destandau in his series reported
$3.5 \%$ and 4 of his patients required reoperation [11]. In our series we experienced $6.15 \%(\mathrm{n}=4)$ of such complications and $3.03 \%(n=2)$ required reoperation.

The popular device which is commonly used is the METRx system for the MED which a serial dilator system utilizing theinterlaminar corridor. It has a telescope mounted at the top end edge of the working channel but as experienced by the senior surgeon this technique causes clutter while working bimanually through the working tube. The other disadvantage is the high cost of the specialized hardware. The Destandau system is the other popular device used worldwide with excellent to good long term result but it has the disadvantage that direct visualization using naked eye or microscope is not possible and also minimally invasive inter-body fusion cannot be performed through this device. The cost of these devices are very high which is a major deterrent in expansion of this technique and as this is an indigenous innovation it has very low cost. The hardware cost if further reduced as it utilizes the conventional discectomy instruments and same telescope which is used in transcranial endoscopic surgeries. 


\section{Conclusions}

Endoscopic discectomy using this conical working tube is a safe and effective technique for lumbar disc prolapse. It has the advantage for early mobilization, short hospital stay and low cost. The long term results are comparable to the conventional techniques.

\section{Corresponding Author}

Dr Kuldeep Yadav, M.Ch. (Neurosurgery),

Assistant Professor of Neurosurgery,

Dr Ram Manohar Lohia Institute of Medical

Sciences, Lucknow,(UP), India

kuldeepyadavrml@gmail.com

\section{References}

1. Atlas SJ, Keller RB, Wu YA, et al: Long-term outcomes of surgical and nonsurgical management of sciatica secondary to a lumbar disc herniation: 10 year results from the Maine Lumbar Spine Study. Spine Phila Pa. 1976;2005:30:927-935.

2. Bakhsh A: Long-term outcome of lumbar disc surgery: an experience from Pakistan. J Neurosurg Spine 2010; 12: 666-670.

3. Bhaisare R, Kamble B, Patond K. Long-Term Results of Endoscopic Lumbar Discectomy by "Destandau's Technique". Asian Spine J. 2016;10(2):289-97.

4. Bhaisare R, Kamble B, Patond K: Asian Spine J. 2016 Apr; 10(2): 289-297. Long-Term Results of Endoscopic Lumbar Discectomy by "Destandau's Technique"

5. Buttermann GR: Treatment of lumbar disc herniation: epidural steroid injection compared with discectomy. A prospective ran- domized study. J Bone Joint Surg 2004;86: 670-679.

6. Casal-Moro R, Castro-Menéndez M, HernándezBlanco M, Bravo-Ricoy JA, Jorge-Barreiro FJ. Long-term outcome after microendoscopic diskectomy for lumbar disk herniation: a prospective clinical study with a 5 -year follow-up. Neurosurgery. 2011;68(6):1568-75;discussion 1575.

7. Chen H. T., Tsai C.H., Chao S. C. et al., "Endoscopic discectomy of L5-S1 disc herniation via an interlaminar approach: prospective controlled study under local and general anesthesia," Surgical Neurology International. 2011; 2(93).

8. Chumnanvej S., Kesornsak W., Sarnvivad P. and Kuansongthum V., "Full endoscopic lumbar discectomy via interlaminar approach: 2-year results in Ramathibodi Hospital," Journal of the Medical Association of Thailand. 2011; 94(12):1465- 1470.

9. Destandau J. Technical features of endoscopic surgery for lumbar disc herniation: 191 patients. Neurochirurgie. 2004;50(1):6-10.

10. Dezawa A. and Sairyo K., "New minimally invasive discectomy technique through the interlaminar space using a percutaneous endoscope," Asian Journal of Endoscopic Surgery. 2011;4(2):94-98.

11. Findlay GF, Hall BI, Musa BS, et al: A 10-year followup of the outcome of lumbar microdiscectomy. Spine (Phila Pa 1976). 1998; 23:1168-1171.

12. Foley KT, Smith MM. Microscopic discectomy. Tech Neurosurg 1997;3:301-307

13. Hsu WK, McCarthy KJ, Savage JW, et al: The Professional Athlete Spine Initiative: outcomes after lumbar disc herniation in 342 elite professional athletes. Spine J. 2011; 11: 180-186

14. Husain M, Jha DK, Agrawal S, Husain N, Gupta RK. Conical working tube: a special device for endoscopic surgery of herniated lumbar discs. Neurosurg J Spine. 2005;2(3):265-70.

15. Hussein M., Abdeldayem A. and Mattar M. M. M., "Surgical technique and effectiveness of microendoscopic discectomy for large uncontained lumbar disc herniations: a prospective, randomized, controlled study with 8 years of follow-up," European Spine Journal, 1992-1999, 2014: 23(9).

16. Jansson KA, Nemeth G, Granath F, et al: Surgery for herniation of a lumbar disc in Sweden between 1987 and 1999. An analysis of 25,576 operations. J Bone Joint Surg Br. 2004; 86- B:841-847.

17. Jensdottir M, Gundmundsson K, Hannesson B et al:20 year follow up after the first microsurgical lumbar discectomies in Iceland. Acta Neurochir(wein) 2007;149:51-58.

18. Jhala A. and Mistry M., "Endoscopic lumbar discectomy: experience of first 100 cases," Indian Journal of Orthopaedics. 2010;44(2):184-190.

19. Kaushal M. and Sen R., "Posterior endoscopic discectomy: results in 300 patients," Indian Journal of Orthopaedics. 2012;46(1):81-85. 
20. Kim C. H., Chung C. K. and Woo J. W., "Surgical outcome of percutaneous endoscopic interlaminar lumbar discectomy for highly migrated disc herniation," Journal of Spinal Disorders and Techniques, 2012.

21. Kim C. H., Chung C. K., Woo J. W., "Surgical outcome of percutaneous endoscopic interlaminar lumbar discectomy for highly migrated disc herniation," Journal of Spinal Disorders and Techniques, 2012.

22. Kim H. S. and Park J. Y., "Comparative assessment of different percutaneous endoscopic interlaminar lumbar discectomy (PEID) techniques," Pain Physician. 2013;16(4):359-367.

23. Kulkarni A. G., Bassi A., and Dhruv A., "Microendoscopic lumbar discectomy: technique and results of 188 cases," Indian Journal of Orthopaedics, 2014: 48(1) 81-87.

24. Li Z.-Z., Hou S.-X., Shang W.-L., Song K.-R. and Zhao H.-L., "The strategy and early clinical outcome of full-endoscopicL5/S1 discectomy through interlaminar approach," Clinical Neurology and Neurosurgery, 2015;(133) 40-45.

25. Mariconda M, Galasso O, Secondulfo V, et al: Minimum 25-year outcome and functional assessment of lumbar discectomy. Spine (Phila Pa. 1976, 2006; 31: 2593-2599.

26. Martinez Quinones JV, Aso J, Consolini F, et al: Long-term outcomes of lumbar microdiscectomy in a working class sample (in Spanish). Neurocirugia 2011; 22: $235-244$.

27. Mixter WJ, Barr JS: Rupture of intervertebral disc with involvement of spinal the canal. N Eng J Med. 1934;211:210-215.
28. Moore AJ, Chilton JD, Uttley D: Long-term results of microlumbar discectomy. Br J Neurosurg. 1994;8:319326.

29. Schoeggl A, Reddy M, Matula C: Functional and economic outcome following microdiscectomy for lumbar disc herniation in 672 patients. J Spinal Disord Tech. 2003;16:150-155.

30. Vik A, Zwartz JA, Hulleberg G, et al: Eight year outcome after surgery for lumbar disc herniation: a comparison of reoperated and not reoperated patients. Acta Neurochir (Wien). 2001;143:607-611.

31. Wang B., L"u G., Patel A. A., Ren P. and Cheng I., "An evaluation of the learning curve for a complex surgical technique: the full endoscopic interlaminar approach for lumbar disc herniations," Spine Journal. 2011;11(2): 122-130.

32. Xue-Song W: a meta-analysis of interlaminar minimally invasive discectomy compared to conventional microdiscectomy for lumbar disk herniation: clinical neurology and neurosurgery. 2014; 127:149-147.

33. Yadav Y. R., Parihar V., Namdev H., Agarwal M., and P. R. Bhatele, "Endoscopic interlaminar management of lumbar disc disease," Journal of Neurological Surgery Part A: Central European Neurosurgery. 2013; 74(2); 77-81.

34. Yoshimoto $\mathrm{M}$, Iwase $\mathrm{T}$, Takebayashi $\mathrm{T}$, Ida $\mathrm{K}$, Yamashita T. Microendoscopic discectomy for far lateral lumbar disk herniation: less surgical invasiveness and minimum 2-year follow-up results. J Spinal Disord Tech. $2014 ; 27(1)$ :E1-7. 